University of Wollongong

Research Online

University of Wollongong in Dubai - Papers

University of Wollongong in Dubai

January 2010

\title{
Explaining virtual community participation: Accounting for the IT artifacts through identification and identity confirmation
}

\author{
Kathy Ning Shen \\ University of Wollongong, kathys@uow.edu.au \\ Mohamed Khalifa \\ University of Wollongong, mkhalifa@uow.edu.au
}

Follow this and additional works at: https://ro.uow.edu.au/dubaipapers

\section{Recommended Citation}

Shen, Kathy Ning and Khalifa, Mohamed: Explaining virtual community participation: Accounting for the IT artifacts through identification and identity confirmation 2010, 1-12.

https://ro.uow.edu.au/dubaipapers/98

Research Online is the open access institutional repository for the University of Wollongong. For further information contact the UOW Library: research-pubs@uow.edu.au 


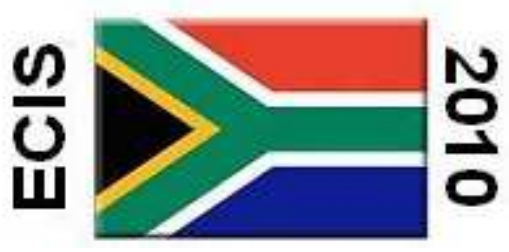

\section{EXPLAINING VIRTUAL COMMUNITY PARTICIPATION: ACCOUNTING FOR THE IT ARTIFACTS THROUGH IDENTIFICATION AND IDENTITY CONFIRMATION}

\begin{tabular}{|r|l|}
\hline Journal: & 18th European Conference on Information Systems \\
\hline Manuscript ID: & ECIS2010-0148.R2 \\
\hline Submission Type: & Research Paper \\
\hline Keyword: & $\begin{array}{l}\text { Computer-mediated communication (CMC), Human factors, Human- } \\
\text { computer interaction, Virtual teams/groups }\end{array}$ \\
\hline \multicolumn{2}{|l}{} \\
\hline
\end{tabular}

\section{scholarONE \\ Manuscript Central}




\title{
EXPLAINING VIRTUAL COMMUNITY PARTICIPATION: ACCOUNTING FOR THE IT ARTIFACTS THROUGH IDENTIFICATION AND IDENTITY CONFIRMATION
}

Kathy Ning Shen, University of Wollongong in Dubai, PO Box 20183, Dubai, United Arab Emirates, kathyshen@uowdubai.ac.ae

Mohamed Khalifa, University of Wollongong in Dubai, PO Box 20183, Dubai, United Arab Emirates, mohamedkhalifa@uowdubai.ac.ae

\begin{abstract}
This study draws upon self-verification theory, social identity theory and self-categorization theory to investigate the dual effects of system design, i.e., identity confirmation (the self) and identification (the community), on virtual community (VC) participation. An important theoretical development is the conceptualization of VC identity and the elucidation of its system design determinants. Community presentation, i.e., system design features for presenting a virtual community identity, is hypothesized to facilitate identification by setting the boundaries for inter-group comparison and highlighting the in-group homogeneity. Furthermore, system design features that prior research identified as determinants for identity confirmation, i.e., self-presentation, deep profiling, and co-presence, are argued to have impacts on identification directly by influencing social comparison and indirectly by making the VC identity attractive. The research model accounts for the dual roles of system design features, i.e., effects on identification and identity confirmation, in explaining VC participation. The implications of these results for both theory and practice are discussed.
\end{abstract}

Keywords: Self-verification, Identification, Virtual Community Participation, Human-computer interaction 


\section{INTRODUCTION}

Virtual communities (VCs), sometimes called online communities, describe the mediated social spaces in the digital environment that allow groups to form and be sustained primarily through ongoing virtual communication processes (Bagozzi and Dholakia 2002). Much evidence has shown their potent influence in bringing together far-flung, like-minded individuals (Hagel and Armstrong 1997) and their commercial and/or social values (Gupta and Kim 2004). Therefore, it is very important to understand the driving forces of $\mathrm{VC}$ participation.

Prior research suggests that two identity processes, i.e., identity confirmation and identification, may entail different practical implications for promoting participation. Research on identification usually emphasizes the collective influences and anonymity of individuals (Postmes et al. 1998) in motivating VC participation, while research on verification proposes making personal identity salient and recognized (Ma and Agarwal 2007). While identity confirmation emphasizes the individual's selfconcept; most prior studies on identification assume antagonism of individuality in the formation of identification, and agree that the salient personal identity would undermine the identification with the collective (Postmes et al. 2000). In the context of VCs, social interaction is enabled and shaped by various IT artefacts, the effects of which may more than often be channelled through multiple competing mechanisms. It is therefore imperative to develop a more comprehensive understanding of the effects of system design by investigating parallel identity processes.

Furthermore, although identification has been demonstrated as a significant determinant of participation, very few studies have investigated its formation in VCs. To date, most research on this topic has been done in the context of formal organizations. Even though a few studies have explored the notion of identification with physical communities, the basis for identification arises from the geographical proximity, and/or members' relational connection, which may not be applicable in the contexts of VCs where strangers communicate in a distributed environment. As most prior studies on VCs only incorporate identification or social identity as an antecedent or moderator to explain members' behavior, we still lack the understanding about how identification with a VC develops in general, and the impacts of IT artifacts in particular.

Thus, in this paper, we aim to examine the dual identity processes in driving VC participation with an emphasis on the antecedents for identification formation. We argue that these two seemingly contradictory identity processes are reconcilable and both of them are influenced by the usage of various system design features. To fill the gap in existing literature on identification formation in VC contexts, we develop the conceptualization of VC identity and propose the system design determinants for identification. Community presentation, i.e., system design features for presenting a virtual community identity, is hypothesized to facilitate identification by setting the boundaries for intergroup comparison and highlighting the in-group homogeneity. Furthermore, system design features that prior research identified as determinants for identity confirmation, i.e., self-presentation, deep profiling, and virtual co-presence, are argued to also have impacts on identification directly by influencing social comparison, and indirectly by making the virtual community identity attractive. The resulting research model enriches the understanding of the complicate implications of system design features by accounting for two competing identity processes, i.e., identification and identity confirmation, providing valuable guidance for $\mathrm{VC}$ moderation and promotion. We also expect this model to guide future empirical endeavour.

This paper is organized as follows. First we set out with a brief review covering two theories, i.e., selfcategorization theory and self-verification theory, and discuss their application in computer-mediated communication (CMC) contexts. Then we develop the research model to explain the relationship between IT artefacts and VC participation as mediated by dual identity processes. This is followed by a discussion of key implications and promising research directions. 
THEORETICAL BACKGROUND

\subsection{Social Identity and Self-categorization Theory}

Social identity was first proposed by Tajfel (1972) and refers to "the individual's knowledge that he belongs to certain social groups together with some emotional and value significance to him of this group membership" (p292). Self-categorization theory is proposed by Turner (1985) and his colleagues (Turner et al. 1987) as an extension of social identity theory. In this theory they specify in detail how social categorization produces prototype-based depersonalization of self and others, and thus generates social identity phenomena. Self-categorization or social categorization of self is a cognitive process whereby self is assimilated to the in-group prototype and depersonalizes selfconception, i.e., self is no longer represented as 'unique individual' but as embodiments of the relevant prototype. Once identified with a social category, the individual tends to define him- or herself in terms of the defining features of the social category which renders the self stereotypically "interchangeable" with other group members, and stereotypically distinct from outsiders (Hogg and Abrams 1988). Accordingly, Ashforth and Mael (1989) define identification as the "perception of oneness with or belongingness" to the social category; Dutton et al. (1994) consider identification as "a cognitive connection between the definition of an organization and the definition a person applies to him- or herself". Once identified with an organizations or a group, either physical or virtual, the individual will exhibit a more autonomous motivation resulting not only in a higher quality of engagement (e.g., greater persistence, effort, etc.) but also in more positive experiences such as enjoyment, sense of purpose, and well-being (Ryan and Deci 2001). Since VCs are usually sustained by voluntarily user-generated content, identification has also been used to explain VC participation (Kankanhalli et al. 2005).

However, most prior research takes identification for granted without considering formation of identification in CMC. One exceptional case is the Social Identity Model of Deindividuation Effect (SIDE) (Spears et al. 2002), where the authors try to explain the relationship between characteristics of CMC and identification. According to SIDE, the resulting effects of deindividuation in CMC are identical to disruptive effects suggested by theories of deindividuation in social psychology (Postmes and Spears 1998): decreased awareness of the social environment and of the self leads to decreased adherence to social norms. Factors that have traditionally been identified as causing deindividuation, such as the combination of anonymity and group immersion (Zimbardo 1969) or interaction via a computer network (Jessup et al. 1990), do not lead to the loss of identity but rather to enhance salience of social identity. This is because the relative lack of individuation in CMC smoothes the difference among the group members. Motivated to reduce the uncertainty in social interaction, members tend to be more sensitive to any salient social identity cues and over-attribute them to group members, leading to an extenuated similarity and unity of the group and causing people to be perceived as group members rather than idiosyncratic individuals (Lea et al. 2001). In short, the deindividuation gives rise to a strong social identification in the context of CMC. Foil and O'Conner (2005), based on SIDE, even advocate the usage of lean media with high role clarity and team legitimacy in order to develop identification in virtual teams.

\subsection{Individuality and Self-verification Theory}

In contrast with social identity approach where the group shapes individuals' self-views, selfverification theory argues for the active role of individuals in shaping their actual and perceived experiences within groups. Self-verification theory (Swann Jr. 1983) assumes that stable self-views provide people with a crucial source of coherence, an invaluable means of defining their existence, and guiding social interaction (cf. (Swann et al. 2003). Thus, people are motivated to validate and confirm their self-concepts, even when those self-concepts are negative (McNulty and Swann Jr. 
1994). In doing so, people allow others or encourage others to see them as they see themselves, a process which helps to obtain coherence in mental and social life and ensures the social interaction unfolding smoothly. Identity confirmation, then, refers to a state that exists when an individual's social environment is consistent with his or her "self-identities" and is conceptualized in terms of congruence between how a group member defines him- or herself and how other group members define that person (Milton and Westphal 2005).

CMC provides individuals another space for exploring new identities and/or extending existing identities (Donath 1999). Although direct application of self-verification theory is still rare, the notion of identity confirmation has been widely applied in prior research. For instance, Hars and Ou (2002) demonstrated peer recognition for the focal person's contribution as a form of extrinsic reward for participating in VCs, leading to a high dedication to open source programming. Chan et al. (2004) further identified different forms of recognition, i.e., identity, expertise and tangible recognition, and reported the positive linkages between recognition and VC participation. Recently, Ma and Agarwal (2007) relying on self-verification theory, proposed that consonance between the focal person's selfconcept and the others' perception of the focal person would enhance the focal person's knowledge contribution to, and satisfaction with VC. All such studies advocate rich media for individuality expression and self-identity communication.

\section{THEORETICAL DEVELOPMENT}

Most prior research follows either social identity theories or self-verification theory, and implicitly treats personal identity and social identity as polar opposites (Tajfel 1978). Individuals and groups as representatives of antagonistic forces, that is, the expression of personal identity as being mutually exclusive with developing strong social identification, e.g., SIDE model. Furthermore, prior research has shown that these two perspectives have distinct implications for community design and management which may undermine each other. For instance, research from self-verification perspective favours the personal identity and encourages self-expression and individuality, which may undermine the process of depersonalization and lead to a low level of identification (e.g., SIDE). On the other hand, reducing identifiability to enhance identification, as suggested in social identity research, may prevent an individual's self-view from getting recognized and confirmed. Are these two theories conflicting or reconcilable?

Examination of these two seemingly competing theories leads us to believe the latter for the following reasons. First, individuality and personal identity expression are an important component in many collective actions. For instance, the explicit expression of personal identities of employees is argued to counteract the negative consequences of super-ordinate identities (Haslam et al. 2003). Second, identification and self-verification reflect identity processes operated at two different levels. While identification emphasizes the comparison between self-views and the collective identity, the selfverification perspective focuses on the negotiation between an individual's identities and the others' perception of the focal person, operating at the relational level. Any individual in a group is inevitably subject to influences from both the collective and the others. Finally, they imply that there are two different motivations related to self-view: while identity confirmation emphasizes the demand for stability of self-view, identification suggests motivation for self-enhancement, self-esteem and uncertainty reduction. These motivations, although different, are not necessarily in conflict. 


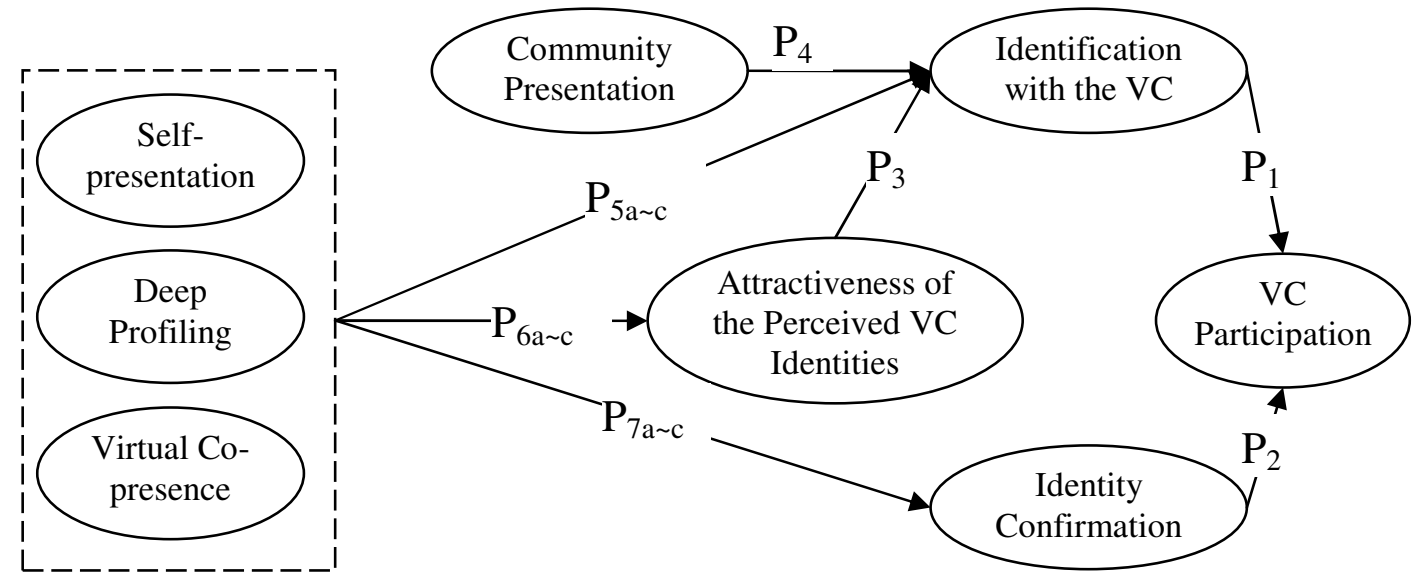

Figure 1. Research Model

Hence, we argue that identification and self-verification are two complementary identity processes in explaining VC participation, and both of them are subject to the influences of IT artefacts (see Figure 1 for the research model). Built upon the work by (Dutton et al. 1994), we elucidate the antecedents of identification with VCs with a focus on IT artefacts. Community presentation, i.e., system design features for presenting a virtual community identity, is hypothesized to facilitate identification by setting the boundaries for intergroup comparison and highlighting the in-group homogeneity. Furthermore, system design features which prior research has identified as determinants for identity confirmation (i.e., self-presentation, deep profiling, and virtual co-presence) are argued to also have impacts on identification not only directly by influencing social comparison, but also indirectly by making the virtual community identity attractive.

\subsection{Determinants of VC Participation}

Identification has been demonstrated to be an important social influence exerted from the collective (in this case, VCs) (Bagozzi and Dholakia 2002). This means that the individual defines him-/herself in terms of the membership in the group. Similar to organizational identification, this study defines VC identification as one's conception of self in terms of the defining features of the VC that renders the self depersonalized. (cf. (Bagozzi and Dholakia 2002). Numerous empirical evidence has shown that identification with an organizations or a group, either physical or virtual, enhances cooperative behavior (Dukerich et al. 2002), participation (Dholakia et al. 2004), and knowledge contribution (Kankanhalli et al. 2005). Thus, we also propose that:

Proposition 1: the member with strong identification with a VC will be more likely to participate in VC discussion.

While influenced by the collective, individuals in a $\mathrm{VC}$ also bring their interaction experience within the group into harmony with their own self-concepts through seeking confirmation from peers (Swann et al. 2003). According to self-verification theory (Swann Jr. 1983), people are motivated to validate and confirm their self-concepts, even when those self-concepts are negative (McNulty and Swann Jr. 1994). In VCs, Hars and Ou (2002) identified peer recognition for the focal person as a form of extrinsic reward for participating in VCs dedicated to open source programming. Chan et al. (2004) further identified different forms of recognition, i.e., identity, expertise and tangible recognition, and demonstrated the positive linkages between recognition and VC participation. Ma and Agarwal (2007), relying on self-verification theory, proposes that consonance between the focal person's selfconcept and the others' perception of the focal person would enhance the focal person's knowledge contribution to and satisfaction with the VC. Thus, we also propose that:

Proposition 2: the member with high identity confirmation will be more likely to participate in VC discussions. 


\subsection{Identification Formation in VCs}

According to Postmes et al. (2005), identification can be either deduced from the collective identity or constructed from social interaction among members. In the prior section, the existence of VC identities was demonstrated from which individual members can derive identification. Meanwhile, in the context $\mathrm{VC}$ where people enjoy more freedom of speech and individuality is usually advocated as a part of VC culture, identification may also be developed and constructed through rich expression of personal identities or individuality. For both paths, IT artefacts play a central role in presenting and communicating identities, and supporting social spaces. Thus, built upon the prior research on identification and human-computer interaction, two categories of factors for VC identification are proposed with an emphasis on the effects of IT artefacts.

\subsubsection{Deduced Identification}

Deduced identification reflects social influences from the collective. How members evaluate a VC identity (e.g., (Dutton et al. 1994) and how the VC identity is presented to make it salient for the basis of self-categorization (e.g., (Bhattacharya and Sen 2003) are two important factors to make this process occur.

Organizational identification literature suggests that an ongoing identity comparison process influences member attitudes toward the organization (Foreman and Whetten 2002), whereby members assess the degree to which their perceptions of the organizational identity are congruent with their selfidentities (Dutton et al. 1994). Perceived organizational identity conceptualized as an individual-level construct refers to the beliefs of a particular individual organizational member and serves as a powerful influence on the degree to which the member identifies with the organization (Dukerich et al. 2002). While perceived organizational identity may be highly correlated with organizational identity -- an organizational-level construct --- the two constructs are conceptually distinct. Moreover, due to the fact that it is always difficult to perfectly socialize members to a collective view, what are perceived by particular members as central, distinct and enduring attributes may not be consistent with what managers want to convey. A perceived organizational identity is viewed as attractive when it fulfils the needs for self-continuity, self-distinctiveness, and self-enhancement, and the attractiveness of this image leads to strong organizational identification (Dukerich et al. 2002).

In the context of VCs, the communication of VC identities is less controllable than that in an organization due to the informal organization and voluntary participation. Members have full flexibility in choosing topics, discussion boards, and partners for interaction. Consequently, imperfect socialization may be more salient and members may vary significantly in the evaluation of VC identities. Despite the differences, members join VCs to fulfil similar needs, e.g., understanding and deepening salient aspects of one's self through social interaction (Dholakia et al. 2004), and seeking self-esteem (Baumeister 1998). As with perceived organizational identity, members assess the attractiveness of the perceived VC identity by how well this image helps maintain the continuity of self-concepts, provides distinctiveness, and enhances self-esteem. To the extent that the perception of VC identities is correspondent with the members' goals and values, i.e., attractiveness of perceived VC identities increases, they are more likely to develop identification with the VC.

Proposition 3: The attractiveness of the member's perceived VC identity is positively associated with the member's strength of VC identification.

Individuals self-categorize on the basis of any of available social identities, which is rather a spontaneous and often unconscious process. According to social identity theories, identity salience, or the extent to which specific identity information dominates a person's working memory, is a key determinant of identification (Hogg and Terry 2000). It is argued that when features of social context serve to make a given social identity salient, the associated process of self-stereotyping has the capacity to consensualize beliefs within a given in-group by 1) enhancing the perceived homogeneity 
of that in-group; 2) generating associated expectations of agreement with other group members on issues relevant to the shared identity; and 3) producing pressure to actively reach consensus in dealing with those issues through mutual influence (Tajfel 1978; Turner 1982; Oakes et al. 1994; Haslam et al. 1999). In particular, when a VC identity is salient, it is likely to increase members' tendency to focus and elaborate on the VC identity over the other competing identities. Therefore, the likelihood of their identification with the $\mathrm{VC}$ is higher.

Identity salience is most often elicited by external factors (Forehand et al. 2002). Prior research has investigated various contextual factors, e.g., group symbols (Cialdini et al. 1976; Devine 1989), priming (Devine 1989), visible differences in dress or physical arrangement of members (Gaertner and Dovidio 1986), visual images and words (Aquino and Reed 2002) and direct intergroup contact (Rodriguez and Gurin 1990). In the context of VCs, however, these contextual factors are mainly integrated into the design of VC websites. VC designers and managers have to rely on IT artefacts to establish the $\mathrm{VC}$ as a viable and meaningful social category in members' minds.

In this research, Community Presentation is proposed to denote VC design features that present constituents of VC identities, including logos and symbols, the statement of purposes, membership policies, community initiatives and promotion, presentation of management teams, interaction states of the $\mathrm{VC}$, demographic features (e.g., size, active members, postings and etc.), unique interface design, and unique functionality design. All these features make VC boundaries visible and help members answer the question, "What does this VC stand for?" Community presentation, therefore, reflects the efforts of VC designers and managers to establish the VC identities as stable, significant and a salient target for identification. To the extent that more constituents of $\mathrm{VC}$ identities are conferred on the $\mathrm{VC}$, the VC becomes a more salient target for identification, and this is especially relevant in VCs that are purely online where perceived legitimacy is often lowest (Fiol and O'Connor 2005). Thus, it is hypothesized that:

Proposition 4: When community presentation includes more constituents of VC identities, members are more likely to identify with the $V C$.

\subsubsection{Individuality Expression and Identification}

Apart from community presentation highlighting intergroup differences and intra-group homogeneity, IT artefacts are also designed for individuation with emphasis on inter-personal difference and diversity. Ma and Agarwal (2007) has identified four categories of VC features, i.e., virtual copresence, persistent labelling, self-presentation, and deep profiling and demonstrated that usage of these features would enhance accountability and perspective taking and consequently facilitate identity confirmation. Although some theories (e.g., SIDE model) following the antagonistic view, that is, the expression of personal identity is mutually exclusive with developing strong social identification, might argue for negative effects of such features on identification. The deterministic nature of this relationship has been questioned recently (see (Spears 2001) for an overview). It is suggested that group formation is facilitated to the extent that it is compatible with the expression of individuality (Haslam et al. 2003; Postmes et al. 2005). Thus, the same VC features usage initially identified as facilitating individual identity expression and confirmation may also have positive impacts on identification, an important indicator for group formation.

Virtual co-presence refers to artefacts that provide a sense of being together with other people in a shared virtual environment (e.g., the 'who is online' feature). By making individuality expression observed and perceived, virtual co-presence is considered as a prerequisite for identity communication (Ma and Agarwal 2007). However, there is not only one implication for such features. According to the social presence theory, the development of a sense of presence implies mutual awareness, psychological involvement, and mutual understanding and is correlated with the feelings of immediacy and intimacy (Biocca et al. 2003). High social presence makes it more likely to build social relationships among members due to its capability to reduce discomfort, as well as increasing predictability and raising the level of affection toward others (cf. (Walther et al. 2001), and increasing 
the possibility to develop attachment to the online community members. In addition, it is a wellknown fact that the observation of in-group member actions gives rise to spontaneous inference of norms or conventions (Postmes et al. 2000). Features supporting the sense of presence make it easier for members to imitate each others' actions, to engage in peer pressure and to create, notice and conform to social conventions (Erickson et al. 2002), thus reinforcing social identification. Accordingly, it is hypothesized that:

Proposition 5a: Usage of virtual co-presence features will be positively related to members' identification with the $V C$.

Self-presentation includes features used to convey personal identities. Features in this category include visual presentations, unique IDs, personal profiles, avatars, signature files and weblogs. Using self-presentation features makes members feel independent as they have a great control over what to present and how to present it. It also enables members to differentiate themselves from others. With various self-presentation features for individuation expression, VCs provide an attractive venue to balance the need to belong with the need to be different. Individuals empowered to express their personal identities will be more likely to develop strong identification (Haslam et al. 2003). In addition, self-presentation features make otherwise anonymous participants more recognizable, enhancing the likelihood of developing attachment and mutual obligation (Blanchard and Markus 2002), which are affective components of identification (Dholakia et al. 2004). Finally, individualityexpression-enabled-self-presentation features may also facilitate inductive identification to occur (Postmes et al. 2005). Thus, it is hypothesized that:

Proposition 5b: Usage of self-presentation features will be positively related to members' identification with the $V C$.

Deep Profiling designates features that help to infer profiles of specific members from historical records. Member profiles can be built through both referential and inferential techniques. Some online communities provide search functions for retrieving the historical activity records of a particular member or of a particular discussion subject. More sophisticated designs incorporate content hit counters, ratings of contributions and participants (usually done by administrators) and peer evaluations (Kelly et al. 2002), as well as displaying the value of contribution (Rashid et al. 2006), oversight or review of the contribution (Cosley et al. 2005). Self-presentation can be considered as referential profiling, while deep profiling constitutes inferential profiling. Similar to self-presentation, deep profiling is another arena for individuality expression. By making activities and interaction history visible and accessible to others, deep profiling individuates each member as a unique member. Moreover, recognition of members' contribution has been demonstrated as a main factor for community commitment (Kang et al. 2005). Accordingly, it is hypothesized that:

Proposition 5c: Other VC members' usage of deep profiling features will be positively related to members' identification with the $V C$.

According to social identity theorists, identification with a social group is mainly derived from the group's ability to fulfil its members' needs (Hogg and Abrams 1988). Individuality expression and facilitation of social interaction are actually advocated as value propositions for most VCs (Dholakia et al. 2004), suggesting the ability to individuate members, in itself, a marker of shared identity or common in-group membership (Marx 1993). Based on a field survey of websites, Eighmey and McCord (1998) conclude that efficiently executed design features can facilitate participants to fulfil various needs. For example, features enabling virtual co-presence cater to the needs for social interaction. Self-presentation and deep profiling features fulfil the needs for self-disclosure. Some of the self-presentation features, e.g., emoticons and avatars, also make the virtual interaction more enjoyable. The consonance between individuality expression features and individual needs makes VC identities more attractive for members. Thus, it is also hypothesized that:

Proposition 6a: Usage of virtual co-presence features will be positively related to members' perceived attractiveness of VC identity. 
Proposition 6b: Usage of self-presentation features will be positively related to members' perceived attractiveness of VC identity.

Proposition 6c: Other VC members' usage of deep profiling features will be positively related to members' perceived attractiveness of VC identity.

\subsection{IT Artefacts and Identity Confirmation}

Consistent with the prior study (Ma and Agarwal 2007), the hypotheses of the impact of virtual copresence, self-presentation and deep profiling on identity confirmation are also included. The original study by (Ma and Agarwal 2007) shows that path coefficients and significance are different for the two sites studied, suggesting that more research with different VCs is necessary to validate and perhaps extend the understanding of the relationship between IT artefacts and identity confirmation. Moreover, as the same artefacts may affect identification and identity confirmation simultaneously, the knowledge of their relative importance for each mechanism will provide valuable guidance for $\mathrm{VC}$ design.

Proposition 7a: Usage of virtual co-presence features will be positively related to members' identity confirmation.

Proposition 7b: Usage of self-presentation features will be positively related to members' identity confirmation.

Proposition 7c: Other VC members' usage of deep profiling features will be positively related to members' identity confirmation.

\section{DISCUSSION AND IMPLICATIONS}

Prior research has suggested two competing identity processes in explaining VC participation with different focuses and design implications. Given the integral nature of $\mathrm{VC}$ contexts, it is therefore, imperative to address the dual effects of system design, i.e., identity confirmation (the self) and identification (the community) on VC participation. Moreover, this study represents the early attempt to address identification formation in VCs by conceptualizing VC identity and the elucidating its system design determinants. Community presentation, representing the effort of $\mathrm{VC}$ designers and managers, is hypothesized to facilitate identification. Furthermore, the relationships between system design features that prior research identified as determinants for identity confirmation and identification are also discussed.

The resulting research model entails several important theoretical implications. First, this study provides a more comprehensive view towards the mechanisms that translate system design into expected individual behaviours. Currently, we have witnessed an obvious trend of integration in many kinds of information system design, leading to two important implications. On the one hand, typologies of IT artefacts need to be developed to provide a complete understanding of system design; on the other hand, multiple psychological/social psychological mechanisms need to be examined simultaneously to gain the insight on the complexity induced by technological settings. In this study, the conceptualization of IT artefacts in VC contexts is extended from the perspective of identity communication. Using "personal vs. collective identities" as a framework, the new conceptualization articulates well the IT artefacts used for VC identities and personal identities communication. Moreover, rather than focusing on single mechanism, this study advances research by accounting for diversity of underlying mechanisms.

The new construct proposed in this study, community presentation, also has important theoretical implications. Most prior VC research takes an individual members' perspective emphasizing the member-sustained aspect of VC sustaining, neglecting the management aspect. In practice, however, $\mathrm{VC}$ designers and managers are actively involved in launching, sustaining, promoting and even 
commercializing VCs. Their efforts, as reflected through the system design, should be considered as an important factor in understanding VC-related phenomenon. This study represents the initial effort to conceptualize the system design from the management perspective.

Another important theoretical contribution of this study is to explore the identification formation in VCs in general and the effects of IT artifacts in particular. Identification has been studied in many contexts, e.g., groups, organizations, communities, and more particularly VCs. In the context of communities, studies on identification have just started and many controversies still remain in several fundamental areas, such as the existence of community identities. In the IS field where VCs have received much interest, most prior studies take identification or theories developed in organizational contexts as given without exploring the specificity brought by IT artifacts. This study advances the theoretical work on identification by conceptualizing VC identities and developing a research model to explain identification formation in VCs; more particularly, the role of the system design for this process has been explored.

The propositions developed in this paper also provide valuable practical guidance for $\mathrm{VC}$ design and management. First our model suggests multiple IT artefacts that VC designers and managers can employ to enhance VC participation. In addition, by elaborating the theoretical underpinning of the effects of system design, the model can also guide the development of new features.

As a theoretical framework, the proposed model offers a clear guideline for future empirical validation and prospect research opportunities. All propositions are ready to be developed into hypotheses and tested in real VCs. Moreover, recognizing the diversity and dynamics inherent in VCs, we also expect the proposed model as a base model which can be used to investigate the diversity in VCs, e.g., gender composition, community stages and etc., which can be included as moderators. Finally, a longitudinal approach could be employed to investigate the dynamics in identity processes, system interaction and VC participation.

\section{References}

Aquino, K. and Reed, A. I. (2002). The self-importance of moral identity. Journal of Personality and Social Psychology, 83, 1423-1440.

Ashforth, B. E. and Mael, F. (1989). Social Identity Theory and the Organization. Academy of Management Review, 14(1), 20-39.

Bagozzi, R. B. and Dholakia, U. M. (2002). Intentional Social Action in Virtual Communities. Journal of Interactive Marketing, 16(2), 2-79.

Baumeister, R. F. (1998). The self. Handbook of Social Psychology. D.T. Gilbert, S.T. Fiske and G. Lindzey. New York, McGraw-Hill, 680-740.

Bhattacharya, C. B. and Sen, S. (2003). Consumer-Company Identification: A Framework for Understanding Consumers' Relationships with Companies. Journal of Marketing, 67(April), 76-88.

Biocca, F., Harms, C. and Burgoon, J. K. (2003). Toward a More Robust Theory and Measure of Social Presence: Review and Suggested Criteria. Presence, 12(5), 456-480.

Blanchard, A. and Markus, M. L. (2002). Sense of Virtual Community --- Maintaining the Experience of Belonging. Proceedings of the 35th Hawaii International Conference on System Sciences.

Chan, C. M. L., Bhandar, M., Oh, L.-B. and Chan, H.-C. (2004). Recognition and Participation in a Virtual Community. Proceedings of the 37th Hawaii International Conference on System Sciences, Hawaii, USA.

Cialdini, R. B., Borden, R. J., Thorne, A., Walker, M. R., Freeman, S. and Sloan, L. R. (1976). Basking in reflected glory: Three (football) field studies. Journal of Personality and Social Psychology, 34, 366?75.

Cosley, D., Frankowski, D., Kiesler, S., Terveen, L., Riedl, J. and CommunityLab (2005). How Oversight Improves Member-Maintained Communities. CHI 2005, Portland, Oregon.

Devine, P. (1989). Stereotypes and prejudice: Their automatic and controlled components. Journal of Personality and Social Psychology, 56, 5-18. 
Dholakia, U. M., Bagozzi, R. P. and Pearo, L. K. (2004). A Social Influence Model of Consumer Participation in Network- and Small-Group-Based Virtual Communities. International Journal of Research in Marketing, 21(3), 241-263.

Donath, J. (1999). Identity and deception in the virtual community. Communities in Cyberspace. M. Smith and P. Kollock. London ; New York, Routledge, 29-59.

Dukerich, J. M., Golden, B. R. and Shortell, S. M. (2002). Beauty is in the Eye of the Beholder: The Impact of Organizational Identification, Identity, and Image on the Cooperative Behaviors of Physicians. Administrative Science Quarterly, 47(September), 507-533.

Dutton, J. E., Dukerich, J. M. and Harquail, C. V. (1994). Organizational Images and Member Identification. Administrative Science Quarterly, 39(2), 239-263.

Eighmey, J. and McCord, L. (1998). Adding Value in the Information Age: Uses and Gratifications of Sites on the World Wide Web. Journal of Business Research, 41, 187-194.

Erickson, T., Halverson, C., Kellogg, W. A., Laff, M. and Wolf, T. (2002). Social Translucence: Designing Social Infrastructures That Make Collective Activity Visible. Communications of the ACM, 45(4), 40-44.

Fiol, C. M. and O'Connor, E. J. (2005). Identification in Face-to-Face, Hybrid, and Pure Virtual Teams: Untangling the Contradictions. Organization Science, 16(1), 19-32.

Forehand, M. R., Deshpande, R. and Reed II, A. (2002). Identity Salience and the Influence of Differential Activation of the Social Self-Schema on Advertising Response. Journal of Applied Psychology, 87(6), 1086-1099.

Foreman, P. and Whetten, D. A. (2002). Members' Identification with Multiple-Identity Organizations. Organization Science, 13(6), 618-635.

Gaertner, S. and Dovidio, J. (1986). Prejudice, discrimination, and racism: Problems, progress and promise. Prejudice, discrimination and racism. J. Dovidio and S. Gaertner. Orlando, FL, Academic Press, 315-332.

Gupta, S. and Kim, H. W. (2004). Enhancing the Commitment to Virtual Community: A Belief and Feeling Based Approach. Twenty-Fifth International Conference on Information Systems.

Hagel, J. and Armstrong, A. (1997). Net Gain: Expanding Markets through Virtual Communities. Mass, Harvard Business School Press.

Hars, A. and Ou, S. (2002). Working for Free? Motivations of Participating in Open Source Projects. International Journal of Electronic Commerce, 6(3), 25-39.

Haslam, S. A., Eggins, R. A. and Reynolds, K. J. (2003). The ASPIRe model: Actualizing social and personal identity resources to enhance organizational outcomes. Journal of Occupational and Organizational Psychology, 76, 83-113.

Haslam, S. A., Oakes, P. J., Reynolds, K. J. and Turner, J. C. (1999). Social Identity Salience and the Emergence of Stereotype Consensus. Personality and Social Psychology Bulletin, 25(7), 809-818.

Hogg, M. A. and Abrams, D. (1988). Social Identifications: A Social Psychology of Intergroup Relations and Group Processes. London, Routledge.

Hogg, M. A. and Terry, D. J. (2000). Social identity and self-categorization processes in organizational contexts. Academy of Management Review, 25(1), 121-140.

Jessup, L. M., Connolly, T. and Tansik, D. A. (1990). Toward a theory of automated group work: The deindividuating effects of anonymity. Small Group Research, 21, 333-348.

Kankanhalli, A., Tan, B. C. Y. and Wei, K.-K. (2005). Contributing Knowledge to Electronic Knowledge Repositories: An Empirical Investigation. MIS Quarterly, 29(1), 113-143.

Kelly, S. U., Sung, C. and Farnham, S. (2002). Designing for Improved Social Responsibility, User Participation and Content in On-line Communities. Proceedings of the SIGCHI Conference on Human Factors in Computing Systems: Changing Our World, Changing Ourselves, Minneapolis, Minnesota, USA.

Lea, M., Spears, R. and de Groot, D. (2001). Knowing me, knowing you: Anonymity effects on social identity processes within groups. Personality and Social Psychology Bulletin, 27, 526-537.

Ma, M. and Agarwal, R. (2007). Through a Glass Darkly: Information Technology Design, Identity Verification, and Knowledge Contribution in Online Communities. Information Systems Research, 18(1), 42-67. 
Marx, K. (1993). The grundrisse: Foundations of the critique of political economy. London, Penguin.

McNulty, S. E. and Swann Jr., W. B. (1994). Identity Negotiation in Roommate Relationships: The Self as Architext and Consequence of Social Reality. Journal of Personality and Social Psychology, 67(6), 1012-1023.

Milton, L. P. and Westphal, J. D. (2005). Identity Confirmation Networks and Cooperation in Work Groups. Academy of Management Journal, 48(2), 191-212.

Oakes, P. J., Haslam, S. A. and Turner, J. C. (1994). Stereotyping and social reality. Oxford, UK, Blackwell.

Postmes, T. and Spears, R. (1998). Deindividuation and antinormative behavior: A meta-analysis. Psychological Bulletin, 123(3), 238-259.

Postmes, T., Spears, R. and Lea, M. (1998). Breaching or building social boundaries? SIDE-effects of computer-mediated communication. Communication Research, 25(6), 689-715.

Postmes, T., Spears, R. and Lea, M. (2000). The Formation of Group Norms in Computer-Mediated Communication. Human Communication Research, 26(3), 341-371.

Postmes, T., Spears, R., Lee, A. T. and Novak, R. J. (2005). Individuality and Social Influence in Groups: Inductive and Deductive Routes to Group Identity. Journal of Personality and Social Psychology, 89(5), 747-763.

Rashid, A. M., Ling, K., Tassone, R. D., Resnick, P., Kraut, R. and Riedl, J. (2006). Motivating Participation by Displaying the Value of Contribution. CHI06, Montreal, Quebec, Canada.

Rodriguez, J. and Gurin, P. (1990). The relationships of intergroup contact to social identity and political conscience. Hispanic Journal of Behavioural Sciences, 12, 235-255.

Ryan, R. M. and Deci, E. L. (2001). To Be Happy or To Be Self-Fulfilled: A Review of Research on Hedonic and Eudaimonic Well-being. Annual Review of Psychology, 52, 141-166.

Spears, R. (2001). The Interaction between the Indiviudal and the Collective Self: Self-categorization in Context. Individual Self, Relational Self, and Collective Self. C. Sedikides and M. B. Brewer. Philadelphia, Taylor \& Francis, 171-198.

Spears, R., Lea, M., Corneliussen, R. A., Postmes, T. and Haar, W. T. (2002). Computer-Mediated Communication as a Channel for Social Resistance: The Strategic Side of SIDE. Small Group Research, 33(5), 555-574.

Swann Jr., W. B. (1983). Identity Negotiation: Where Two Roads Meet. Journal of Personality and Social Psychology, 53(6), 1038-1051.

Swann, W. B. J., Rentfrow, P. J. and Guinn, J. S. (2003). Self-Verification: The Search for Coherence. Handbook of Self and Identity. M. R. Leary and J. P. Tangney. New York, Guilford Press, 367-383.

Tajfel, H. (1972). La categorisation sociale (Social categorization). Introduction a la Psychologie Sociale. S. Moscovici. Paris, Larouse, 272-302.

Tajfel, H. (1978). Differentiation Between Social Groups: Studies in the Social Psychology of Intergroup Relations. London, Academic Press.

Turner, J. C. (1982). Towards a cognitive redefinition of the social group. Social Identity and Intergroup Relations. H. Tajfel. Cambridge, Cambridge University Press, 15-40.

Turner, J. C. (1985). Social categorization and the self-concept: A social cognitive theory of group behavior. Advances in Group Processes. E. J. Lawler. Greenwich, CT, JAI Press. 2, 77-122.

Turner, J. C., Hogg, M. A., Oakes, P. J., Reicher, S. D. and Wetherell, M. S. (1987). Rediscovering the Social Group: A Self-categorization Theory. Oxford, Blackwell.

Walther, J. B., Slovacek, C. L. and Tidwell, L. C. (2001). Is a Picture Worth a Thousand Words? Communication Research, 28(1), 105-134.

Zimbardo, P. G. (1969). The human choice: Individuation, reason, and order vs. deindividuation, impulse and chaos. Nebraska Symposium on Motivation. W. J. Arnold and D. Levine. Lincoln, University of Nebraska Press. 17, 237-307. 